\title{
Development and Assessment of Functional Properties of Curry Leaf based Herbal Tea
}

\author{
B. Ubashana ${ }^{1 *}$, M. Mohanalakshmi ${ }^{1}$, N. Shoba ${ }^{1}$ and P. Vennila ${ }^{2}$ \\ ${ }^{1}$ Department of Spices and Plantation Crops, HC\&RI, TNAU, Coimbatore, Tamil Nadu, India \\ ${ }^{2}$ Department of Food science and Nutrition, Post-Harvest Technology Centre, Agricultural \\ Engineering College and Research Institute, TNAU, Coimbatore, Tamil Nadu, India \\ *Corresponding author
}

\section{A B S T R A C T}

\section{Keywords}

Curry leaves,

Herbal tea,

Functional properties,

Nutraceutical product

Article Info

Accepted:

22 October 2020

Available Online:

10 November 2020
Herbal tea is often combined to create delicious taste with unique flavours and mainly enjoyed as a natural caffeine-free alternative to standard teas. In the present study, curry leaves based herbal tea were developed with the combination of moringa, amla, ginger, celery and sweet basil. The selected spices and herbs were subjected to drying conditions to obtain maximum retention of bioactive compounds. All the selected spices and herbs were dried by cabinet tray drying method to attain a brittle texture for easy blending. The herbal combination developed was packed as dip tea bags. Total phenols, total flavonoids, total antioxidant activity, tannin, ascorbic acid, iron and organoleptic characteristics were investigated by standard methods. Results indicated that the herbal tea combination exhibited highest total phenol content $(85.59 \mathrm{mg} \mathrm{GAE} / \mathrm{g})$, total flavonoid content (19.38 $\mathrm{mg} \mathrm{QE} / \mathrm{g})$, total antioxidant activity $(6.27 \mathrm{~g} / 100 \mathrm{~g})$, tannin content $(60.77 \mathrm{mg}$ tannic acid/g), ascorbic acid content $(1.88 \mathrm{~g} / 100 \mathrm{~g})$ and iron content $(55.80 \mathrm{mg} / 100 \mathrm{~g})$ than commercial green tea. Organoleptic evaluation revealed that the combination of 50 per cent of curry leaves, 20 per cent of amla, 10 per cent of moringa and dry ginger and 50 per cent of celery and sweet basil based herbal tea had highest overall acceptability and therefore curry leaf based herbal tea can be used as an alternative to commercial green tea with varying health benefits.

\section{Introduction}

Spices and herbs had been used as food and medication for centuries. In the renovation of the high quality of human existence, it plays a widespread role by providing an abundant source of antioxidants and medicinal constituents (Craig, 1999). Nutraceutical has been defined as "food or part of food" which offers scientific or health benefits such as disease prevention and treatment (Dureja, et al., 2003).

The curry leaves (Murraya koenigii) are a leafy vegetable of the Rutaceae family. Pharmacological functions of plants, such as cardiovascular activity, reducing properties of anti-diabetic and cholesterol, antimicrobial activity, anti-ulcer activity, antioxidant properties, anti-diarrheal activity. It has 
vitamin $A$, vitamin $B$, vitamin $C$, vitamin $B_{2}$, calcium and iron in plenty (Singh et al., 2014). Moringa oleifera Lam.is an affordable and readily available supply of major crucial vitamins and nutraceuticals, and it has the potential to remove malnutrition (Kunyangaet al., 2013). Amla possesses antipyretic, analgesic, antitussive properties. Amla tea is highly consumed for fat burn and weight reduction. (Bhandari et al., 2012). Ginger tea treats nausea, alleviates muscle pain, strong anti-inflammatory, could lower blood sugar, reduces hazard for coronary heart sickness, prevents and fights cancer, lessen menstrual cramps, can enhance digestion and respiration (Shahrajabian et al., 2019). The juice extracted from the petioles of celery may be used for edema, rheumatic tendencies, gout, flatulence, continual pulmonary catarrh, tendencies closer to obese and shortage of appetite (Tyagi et al., 2013). Ocimum basilicum is used to treat respiratory issues, arthritis, menstrual cramps, stomach conditions, cancer and neurode generated diseases (Purushothaman et al., 2018).

Herbal teas are actually mixtures of many ingredients and are extra-accurately referred to as 'Tisanes.' Tisanes consist of mixtures of dried leaves, seeds, grasses, nuts, barks, fruits, flowers or other botanical elements that give them their taste and provide the benefits of herbal teas (Killedar et al., 2017). Green teas are usually produced from younger leaves, leaf buds and internodes of the tea plant Camellia sinensis or Camellia assamica. It contains caffeine and it has been used to increase alertness.

Caffeine is a bitter substance that stimulates critical nervous system that ends in harmful effects on human body (Heaney, 2002). Tisanes contain no caffeine, this might be the largest benefit of tisanes, and due to the fact caffeine content additionally can cause nervousness, sleeplessness and anxiety.
Therefore, herbal teas were developed using curry leaves to improve the flavour, aroma and health promoting properties that could substitute commercial green tea. The herbs specifically Murraya koenigii leaves, Moringa oleifera leaves, Phyllanthus emblicaberries, Zingiber officinale rhizome, Apium graveolens leaves, Ocimum basilicum leaves had been used to develop a healthy ideal and safe tea appropriate for all age groups.

\section{Materials and methods}

\section{Sample collection}

The fresh leaves of Murraya koenigii were collected from the organic curry leaf field, Karamadai, Coimbatore. Organic curry leaves were collected during November 2019. The environmental conditions had mean maximum/minimum temperature of $28 / 22^{\circ} \mathrm{C}$ and precipitation of $9 \mathrm{~mm}$. The leaves of Moringa oleifera were obtained from Orchard, Tamil Nadu Agricultural University, Coimbatore. Fresh (Phyllanthus emblica) Amla berries, Celery (Apium graveolens), Sweet basil (Ocimum basilicum), Ginger (Zingiber officinale) were obtained from Kovai Pazhamudhir Nilayam, RS Puram West, Coimbatore.

\section{Standardization of processing methods of selected spices and herbs}

The selected spices and herbs were subjected to dry to obtain the maximum retention of bioactive compounds. Fresh curry leaves were carefully inspected and all foreign materials removed and then gently rinsed in tap water. In processing, the cleaned curry leaves, moringa leaves, amla berries, ginger slices, celery leaves, sweet basil leaves were spread thinly on aluminium trays of the cabinet drier and dried the curry leaves, moringa, celery and sweet basil at a temperature of $60{ }^{\circ} \mathrm{C}$ for 
3 hours, amla and ginger were dried at a temperature of $60^{\circ} \mathrm{C}$ for 4 hours. Herbal tea powder was developed using the method described by Giao et al., (2009). To achieve standardized particle size for herbal tea powder, the above refined and dried samples were powdered using a blender and passed through an aluminium sieve $(1 \mathrm{~mm})$.

\section{Formulation of blended herbal tea powder}

The curry leaf based herbal tea was standardized by the preparation of teas with different combinations. The combination of 50 per cent curry leaves, 20 per cent dry amla berries, 10 per cent moringa leaves and dry ginger, and 5 per cent celery and sweet basil was the most acceptable sensory score. The herbal tea powder was prepared as a bag of dip tea. Hasthip empty tea bags with string heal filter paper, sold by Elephant Boat Ecommerce private limited, Thane, Maharashtra was purchased through online for the preparation of dip tea bag (Table 1).

\section{Standardization of herbal tea infusions}

The prepared herbal tea blend (2g) was packed in non-drip tea bag. The herbal infusions were prepared by dipping tea bag in $150 \mathrm{ml}$ of hot water for 1,2 and 3 minutes (Horzic et al., 2009). The organoleptically acceptable time for infusion is 3 minutes and it was standardized.

\section{Bioactive compounds analyzed for antioxidant activity}

\section{Sample extraction}

The herbal tea powder was purified using a Whatman No. 41 filter paper. The tea samples were then extracted with 80 per cent ethanol by centrifugation @ 3000 rpm for 20 minutes. So the supernatant was collected and stored for further analysis at $4^{\circ} \mathrm{C}$.

\section{Total Phenol Content (TPC)}

Spectrophotometrically, the overall phenolic content in herbal tea infusions was measured using a Folin-Ciocalteu test as described by Harbourne et al., 2009. UV-VIS Spectrophotometer had read the absorbance at $765 \mathrm{~nm}$. The sample's overall phenol content was measured as mg equivalent of Gallic acid (mg GAE)/ml of tea extract.

\section{Total Flavonoid Content (TFC)}

The total content of flavonoids in herbal tea infusions has been analyzed by the method of Singh et al., 2012. UV-VIS Spectrophotometer was used to calculate the absorbance at $510 \mathrm{~nm}$. The findings were expressed as $\mathrm{mg}$ of the corresponding quercetin $(\mathrm{mg} \mathrm{QE}) / \mathrm{ml}$ sample of the tea.

\section{Total anti-oxidant activity (FRAP method)}

The total antioxidant activity of herbal tea infusions were determined by FRAP assay, it is a method for measuring total reducing power of electron donating substances, was carried out according to the procedure of Benzie and Strain,1999. The absorbance was measured at $593 \mathrm{~nm}$ and the result was expressed as $\mathrm{mg} / \mathrm{g}$ of dry sample.

\section{Tannin content}

Tannin content of the herbal tea infusions was determined by Vanillin Hydrochloride Method as described by Sadasivam and Manickam, 1996. The absorbance was read at $500 \mathrm{~nm}$ in spectrophotometer. The tannin content was expressed in mg tannic acid per gram of sample.

\section{Ascorbic acid content}

The estimation of ascorbic acid in herbal tea sample was determined by titration method, 
(Cunniff, 1995). The ascorbic content was expressed in $\mathrm{mg}$ per $100 \mathrm{~g}$ of tea sample.

\section{Iron content}

The iron content of herbal tea samples was determined by AAS method (Mertens, 2005).The absorbance was read in spectrophotometer at $540 \mathrm{~nm}$. The iron content was expressed in mg per100 gram of sample.

\section{Sensory evaluation}

Organoleptic evaluation was conducted as per the method described by Watts et al., 1989. A panel of 10 members evaluated the prepared herbal tea infusions. The tea samples were approximately $60{ }^{\circ} \mathrm{C}$ to $70{ }^{\circ} \mathrm{C}$ at the time of tasting. The organoleptic evaluation sessions were conducted one hour before lunch under adequate conditions of temperature, humidity and illumination. The panelists were asked to score the colour, appearance, flavour, texture, taste and over all acceptability of the herbal tea infusions on a scale of 9 to 1 point hedonic scale.

\section{Statistical analysis}

The results were expressed as mean \pm standard deviation. All measurements werereplicated three times.Factorial Completely Randomized Design (FCRD) was applied for the analysis (Gomez and Gomez, 1984).

\section{Results and Discussion}

\section{Total Phenol Content (TPC)}

The total phenolic content of herbal tea combination was $85.59 \mathrm{mg}$ GAE/gram.Pal et al., (2012) revealed that the total phenol content in green tea was found to be $(36.01+$ $0.89 \mathrm{mg} \mathrm{GAE} / \mathrm{g})$. The results indicated that the total phenol content in herbal tea combination is significantly higher than green tea. This may be due to the presence of moringa leaves, amla berries and curry leaves in herbal tea blends which leads to degradation of tannins to simple phenolic compounds. The total phenol content is responsible for the antioxidant activity.

\section{Total flavonoid content}

The total flavonoid content of herbal tea combination was $19.38 \mathrm{mg} \mathrm{QE} / \mathrm{g}$. Barreira et al., (2013) revealed that total flavonoid content in $C$. sinensis tea is $0.13 \mathrm{mg} \mathrm{CE} / \mathrm{ml}$.

The results indicated that the flavonoid content in herbal tea combination is significantly higher than green tea. This may be due to the presence of celery leaves in herbal tea blends, because celery contains high content of flavonoids such as apigenin, it inhibits aldose reductase enzyme, which reduces the complications of diabetes and other diseases (Niaz, 2013) (Table 2).

\section{Total antioxidant activity}

The total antioxidant activity of herbal tea combination was $6.27 \mathrm{~g} / 100 \mathrm{~g}$. Hashish et al., (2018) revealed that the antioxidant content of green tea ranged from 11.92 to 52.82 $\mathrm{mg} / 100 \mathrm{~g}$.

The results indicated that the total antioxidant content in herbal tea combination is significantly higher than green tea. This may be due to the presence of amla berries in herbal tea blends, because amla evaluating its role as an antioxidant, in ulcer prevention, for people with diabetes, for mental and memory effects, and its anti-inflammatory benefits (Dasaroju et al., 2014). The mechanism behind antioxidant activity is due to recycling sugar moiety and converting the polyphenol into tannins of medium and high molecular weight. The potent antioxidant ellagic acid 
found in amla can inhibit gene mutations and repair chromosomal abnormalities (Govind $e t$ al., 2011).

\section{Tannin content}

The tannin content of herbal tea combination was $60.77 \mathrm{mg}$ tannic acid/g. Bizuayehu et al., (2016), revealed that the total tannin content among the various tea brands was found to be $5.64 \pm 0.39$ to $7.45 \pm 0.27 \mathrm{mg}$ TAE $/ g$ DW corresponding to the brand name Dire tea to green tea.

The results indicated that the tannin content in herbal tea combination is significantly higher than green tea. This may be due to the presence of curry leaves in herbal tea blends, because presence of tannins in pharmacologically potent leaves can help to prevent and also combat various types of health ailments, the underlying mechanism being the radical scavenging and antioxidant potential of tannins (Ghosh, 2015).

\section{Ascorbic acid content}

The ascorbic acid content of herbal tea combination was $1.88 \mathrm{~g} / 100 \mathrm{~g}$. Neog et al., (2020), revealed that the ascorbic acid content in green tea was found to be $(9.31 \mathrm{mg} / 100 \mathrm{~g}$ to $14.63 \mathrm{mg} / 100 \mathrm{~g}$ ).

Table.1 Combination details

\begin{tabular}{|c|c|c|c|c|c|c|}
\hline \multirow[b]{2}{*}{ Combinations } & \multirow{2}{*}{$\begin{array}{c}\text { Primary herb (\%) } \\
\text { Curry leaves }\end{array}$} & \multicolumn{2}{|c|}{ Supporting herb (\%) } & \multicolumn{3}{|c|}{ Activating herb(\%) } \\
\hline & & Moringa & Amla & Ginger & Celery & Sweet basil \\
\hline $\mathbf{C}_{1}$ & 50 & 10 & 20 & 10 & 5 & 5 \\
\hline $\mathbf{C}_{2}$ & 50 & 5 & 25 & 5 & 5 & 10 \\
\hline $\mathbf{C}_{3}$ & 50 & 5 & 25 & 5 & 10 & 5 \\
\hline $\mathrm{C}_{4}$ & 25 & 15 & 15 & 15 & 15 & 15 \\
\hline $\mathrm{C}_{5}$ & 50 & 10 & 20 & 10 & 10 & - \\
\hline $\mathrm{C}_{6}$ & 50 & 10 & 20 & - & 10 & 10 \\
\hline $\mathbf{C}_{7}$ & 50 & 10 & 20 & 10 & - & 10 \\
\hline $\mathrm{C}_{8}$ & \multicolumn{6}{|c|}{ Control - commercial green tea } \\
\hline
\end{tabular}

Table.2 Biochemical parameters of developed nutraceutical product

\begin{tabular}{|l|l|}
\hline Biochemical parameters & Herbal tea powder $\left(\mathbf{C}_{\mathbf{1}}\right)$ \\
\hline Total Phenol Content $(\mathbf{m g}$ GAE/g) & $85.59 \pm 0.816476$ \\
\hline Total Flavonoid Content $(\mathbf{m g} \mathbf{Q E} / \mathbf{g})$ & $19.38 \pm 1.006645$ \\
\hline Total antioxidant activity $(\mathbf{g} / \mathbf{1 0 0 g})$ & $6.27 \pm 0.008478$ \\
\hline Tannin content $(\mathbf{m g}$ tannic $\mathbf{a c i d} / \mathbf{g})$ & $60.77 \pm 0.790021$ \\
\hline Ascorbic acid content $\mathbf{( g / 1 0 0} \mathbf{g})$ & $1.88 \pm 0.076589$ \\
\hline Iron content $(\mathbf{m g} / \mathbf{1 0 0 g})$ & $55.80 \pm 0.98583$ \\
\hline
\end{tabular}

*Values are expressed as mean \pm standard deviation 
Table.3 Sensory evaluation of developed nutraceutical product

\begin{tabular}{|c|c|c|c|c|c|}
\hline \multirow{2}{*}{ Combinations } & \multicolumn{5}{|c|}{ Sensory parameters } \\
\cline { 2 - 6 } & $\begin{array}{c}\text { Appearance } \\
\text { and colour }\end{array}$ & Flavour & Consistency & Taste & $\begin{array}{c}\text { Overall } \\
\text { acceptability }\end{array}$ \\
\hline $\mathbf{C}_{\mathbf{1}}$ & 9.50 & 9.60 & 8.50 & 9.60 & 9.30 \\
\hline $\mathbf{C}_{\mathbf{2}}$ & 8.50 & 9.00 & 8.50 & 8.00 & 8.50 \\
\hline $\mathbf{C}_{\mathbf{3}}$ & 9.30 & 9.20 & 8.50 & 9.20 & 9.05 \\
\hline $\mathbf{C}_{\mathbf{4}}$ & 8.00 & 7.60 & 8.50 & 7.50 & 7.90 \\
\hline $\mathbf{C}_{\mathbf{5}}$ & 9.30 & 7.00 & 8.50 & 7.00 & 7.95 \\
\hline $\mathbf{C}_{\mathbf{6}}$ & 9.00 & 8.50 & 8.50 & 9.00 & 8.75 \\
\hline $\mathbf{C}_{\mathbf{7}}$ & 9.40 & 8.90 & 8.50 & 9.30 & 9.03 \\
\hline $\mathbf{C}_{\mathbf{8}}$ & 7.60 & 7.30 & 8.50 & 7.10 & 7.63 \\
\hline
\end{tabular}

Fig.1 Sensory evaluation of developed nutraceutical product

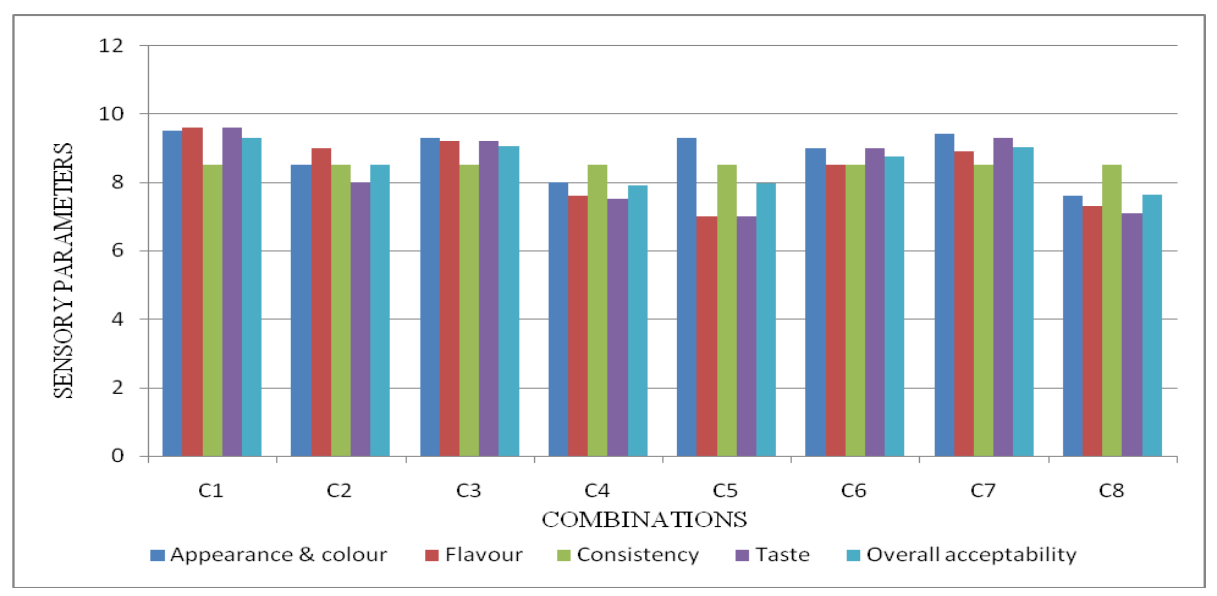

The results indicated that the ascorbic acid content in herbal tea combination is significantly higher than green tea. This may be due to the presence of amla berries in herbal tea blends, because amla is one of the richest natural sources of ascorbic acid and plays a vital role in preventing innumerable health disorders. It is considered to be a safe herbal medicine without any adverse effects (Kulkarni et al., 2018).

\section{Iron content}

The iron content of herbal tea combination was $55.80 \mathrm{mg} / 100 \mathrm{~g}$. Reto et al., (2007) revealed that the tea contains only trace amounts of iron levels were between 0.020 to
$0.128 \mathrm{mg} / \mathrm{l}$. The results indicated that the iron content in herbal tea combination is significantly higher than green tea. This may be due to the presence of curry leaves, moringa, amla and celery in herbal tea blends, because the amla berries are very high in vitamin $\mathrm{C}$ which further supports the absorption of iron in curry leaves, moringa and celery (Hallberg et al., 1982).

\section{Sensory evaluation}

A panel of semi-trained members had assessed the organoleptic evaluation of the developed herbal tea combination. The results showed that the first combination $\mathrm{C}_{1}$ scored the higher sensory scores. Sensory evaluation 
of herbal tea was done for overall acceptance (colour, aroma, flavour, astringency) by 10 members on the basis of 9-point Hedonic scale (Fig. 1 and Table 3).

In conclusion on the basis of the results obtained from the present investigation showed that curry leaves, moringa, amla, ginger, celery, sweet basil and the formulation mixture of these herbs showed that they can be proven to be an excellent source of nutraceuticals and flavouring agents. Based on these findings, it is recommended to use curry leaves for herbal tea preparation since it possessed high antioxidant activity and high iron absorption which is beneficial for human health. Several health benefits included in the blended formula make it a great rejuvenator for physical and psychological wellbeing. While many health benefits are also attributed to green tea, it has been found, according to some unpublished studies, that the sensory appeal of green tea is not very attractive because of the lack of distinct flavour properties. Thus, mixing herbs (Curry leaves, Moringa, Amla, Ginger, Celery and Sweet basil) may be a good idea for the production of flavoured herbal tea, which not only adds to its appeal, but also makes it a wonderful product in the human health sense. Curry leaves are rich in bioactive compounds that are used to cure several issues such as weight loss, dysentery care, constipation and diarrhea, relieves morning sickness and nausea, kills bacteria, good for diabetes and eyesight, treat wounds, burns and skin rashes. Consumption of curry leaves is very rare among the general public although it is rich in bioactive compounds. It can be used to prepare beverage in order to exploit the bioactive compounds of curry leaves. Therefore it is suggested that curry leaves based herbal teas can be produced that will be highly appropriate among all age groups. Because sensory appeal matters more to consumers than health or nutritional benefits, the above-mentioned infusion will give them new alternatives to tradition.

\section{References}

Barreira, J., Morais, A. L., Ferreira, I. C., and Oliveira, M. B. P. P. (2013).Insights on the formulation of herbal beverages with medicinal claims according with their antioxidant properties. Molecules, 18(3), 2851-2863.

Benzie, I. F., and Strain, J. J. (1999). Ferric reducing/antioxidant power assay: direct measure of total antioxidant activity of biological fluids and modified version for simultaneous measurement of total antioxidant power and ascorbic acid concentration. In Methods in enzymology, 299, 15-27.Academic press.

Bhandari, P. R., and Kamdod, M. A. (2012). Emblica officinalis (Amla): A review of potential therapeutic applications. International Journal of Green Pharmacy (IJGP), 6(4).

Bizuayehu, D., Atlabachew, M., and Ali, M. T. (2016). Determination of some selected secondary metabolites and their in vitro antioxidant activity in commercially available Ethiopian tea (Camellia sinensis). Springer Plus, 5(1), 412.

Craig, W. J. (1999). Health-promoting properties of common herbs. The American journal of clinical nutrition, 70(3), 491s-499s.

Cunniff, P. (1995). Official methods of analysis. Association of Official Analytical Chemists (AOAC).16th ed. Arlington, Virginia, USA.

Dasaroju, S., and Gottumukkala, K. M. (2014). Current trends in the research of Emblica officinalis (Amla): A pharmacological perspective. Int $J$ Pharm Sci Rev Res, 24(2), 150-159.

Dureja, H., Kaushik, D., and Kumar, V. 
(2003).Developments in nutraceuticals. Indian journal of pharmacology, 35(6), 363-372.

Ghosh, D. (2015). Tannins from foods to combat diseases. Int $J$ Pharm Res Rev, 4(5), 40-44.

Gião, M. S., Pereira, C. I., Fonseca, S. C., Pintado, M. E., and Malcata, F. X. (2009). Effect of particle size upon the extent of extraction of antioxidant power from the plants Agrimonia eupatoria, Salvia sp. and Saturejamontana. Food Chemistry, 117(3), 412-416.

Gomez, K. A., and Gomez, A. A. (1984). Statistical procedures for agricultural research.John Wiley and Sons.

Govind, P. (2011). Some important anticancer herbs: a review. Int Res J Pharm, 2(7), 45-52.

Hallberg, L., and Rossander, L. (1982). Absorption of iron from Western-type lunch and dinner meals. The American journal of clinical nutrition, 35(3), 502509.

Harbourne, N., Marete, E., Jacquier, J. C., and O'Riordan, D. (2009). Effect of drying methods on the phenolic constituents of meadowsweet (Filipendulaulmaria) and willow (Salix alba). LWT-Food Science and Technology, 42(9), 1468-1473.

Hashish, A., Zein, H., and El-BhnsawyRasha, M. (2018). Evaluation of total phenolic compounds, flavonoids and antioxidant activity of black and green tea drink among some available brands in the Egyptian market, Current Science International, 7(4), 721-730.

Heaney, R. P. (2002). Effects of caffeine on bone and the calcium economy. Food and Chemical Toxicology, 40(9), 12631270.

Horžić, D., Komes, D., Belščak, A., Ganić, K. K., Iveković, D., and Karlović, D. (2009). The composition of polyphenols and methylxanthines in teas and herbal infusions. Food chemistry, 115(2), 441448.

Killedar, S. G., Pawar, A. V., and Suresh Killedar, C. (2017). Preparation of herbal tea from mulberry leaves. Journal of Medicinal Plants Studies, $5(2), 325-328$.

Kulkarni, K. V., and Ghurghure, S. M. (2018).Indian gooseberry (Emblicaofficinalis): complete pharmacognosy review. Int $J$ Chem Studies, 2, 5-11.

Kunyanga CN, Imungi JK, Vellingiri V (2013). Nutritional evaluation of indigenous foods with potential foodbased solution to alleviate hunger and malnutrition in Kenya. $J$ ApplBiosci 67:5277-5288.

Mertens, D. (2005). AOAC official method 922.02. Plants preparation of laboratuary sample. Official Methods of Analysis.Chapter, 3, 20877-2417.

Neog, M., Das, P., and Saikia, G. K. (2020).Changes in Phytochemicals during Processing of Green Tea. Int. J. Curr. Microbiol. App. Sci, 9(1), 414425.

Niaz, K. (2013). Antihyperglycemic/ hypoglycemic effect of celery seeds (ajwain/ajmod) in streptozotocin induced diabetic rats. Journal of Rawalpindi Medical College, 17(1), 134-137.

Pal, S., Ghosh, D., Saha, C., Chakrabarti, A. K., Datta, S. C., and Dey, S. K. (2012). Total polyphenol content, antioxidant activity and lipid peroxidation inhibition efficacy of branded tea (Camellia sinensis) available in India. IJTS, 8, 1320.

Purushothaman, B., PrasannaSrinivasan, R., Suganthi, P., Ranganathan, B., Gimbun, J., and Shanmugam, K. (2018).A comprehensive review on Ocimum basilicum. Journal of Natural Remedies, 18(3), 71-85. 
Reto, M., Figueira, M. E., Filipe, H. M., and Almeida, C. M. (2007). Chemical composition of green tea (Camellia sinensis) infusions commercialized in Portugal. Plant foods for human nutrition, 62(4), 139.

Sadasivam, S., and Manickam, A. (1996).Biochemical methods 2nd edn. New Delhi: New Age International Publishers (P) Ltd, 107-109.

Shahrajabian, M. H., Sun, W., and Cheng, Q. (2019). Clinical aspects and health benefits of ginger (Zingiber officinale) in both traditional Chinese medicine and modern industry. Actaagriculturae scandinavica, section $b$-Soil and Plant Science, 69(6), 546-556.

Singh, S., More, P., and Mohan, S. M. (2014). Curry leaves (Murraya koenigii Linn. Sprengal)-a mircale plant. Indian Journal of Scientific Research, 4(1), 46-
52.

Singh, V., Guizani, N., Essa, M. M., Hakkim, F. L., and Rahman, M. S. (2012).Comparative analysis of total phenolics, flavonoid content and antioxidant profile of different date varieties (Phoenix dactylifera L.) from Sultanate of Oman. International Food Research Journal, 19(3), 1063-1070.

Tyagi, S., Chirag, P., Dhruv, M., Ishita, M., Gupta, A., Usman, M., Nimbiwal, B., and Maheshwari, R. (2013). Medical benefits of Apium graveolens (celery herb). Journal of Drug Discovery and Therapeutics, 1(5), 36-38.

Watts, B. M., Ylimaki, G. L., Jeffery, L. E., and Elias, L. G. (1989). Basic sensory methods for food evaluation. IDRC, Ottawa, ON, CA.

\section{How to cite this article:}

Ubashana, B., M. Mohanalakshmi, N. Shoba and Vennila, P. 2020. Development and Assessment of Functional Properties of Curry Leaf based Herbal Tea. Int.J.Curr.Microbiol.App.Sci. 9(11): 3148-3156. doi: https://doi.org/10.20546/ijcmas.2020.911.379 